\title{
DISCRIMINACIÓN, DEGRADACIÓN Y BIOLOGICISMO: EL TRATAMIENTO DADO A LOS ÚLTIMOS PELDAÑOS DE LA CLASE TRABAJADORA EN CÓRDOBA, ARGENTINA
}

\author{
Discrimination, degradation and biologicism: \\ the treatment given to the last rungs of the working class in Córdoba, \\ Argentina
}

Juan Manuel Zeballos'

\begin{abstract}
Resumen
Este artículo, producto de una labor etnográfica, propone señalar las valoraciones degradantes y las prácticas de discriminación imperantes sobre los peldaños más deprimidos de la clase trabajadora en Córdoba, Argentina. Atender a tal propósito demandó adentrarse en los espacios en que este sector de la clase obrera vive -o vive mal-: las villas. ${ }^{2}$ Luego del trabajo de campo se puede concluir que a la parte más empobrecida de la clase asalariada, la cual se haya en condiciones materiales de existencia caracterizadas por la informalidad, precariedad laboral y el desempleo, cuyo correlato son las residencias sumamente precarias, con acceso irregular, limitado, y sin acceso a los servicios de agua, electricidad y gas respectivamente, en condiciones de hacinamiento y con peligros de localización, se la estigmatiza y discrimina. Asimismo, más allá del reconocimiento, de la percepción de las prácticas discriminatorias por parte de los discriminados, tanto la baja estimación como la discriminación tienen la funcionalidad de legitimar socialmente las condiciones miserables de vida a la que está sometida esta porción de la población. En este trabajo se adelanta parte de los resultados obtenidos en una investigación de doctorado, la cual tiene por temáticas la existencia degradada ${ }^{3}$ y el diacrítico-estigma biologicista ${ }^{4}$ en la ciudad de Córdoba, Argentina.
\end{abstract}

Palabras clave: clase trabajadora, estigmatización, discriminación, biologicismo.

\begin{abstract}
This article, product of an ethonographic work, proposes to point out the degrading evaluations and prevailing discriminatory practices on the most depressed rungs of the working class in Córdoba, Argentina. Attending to such purpose demanded to enter into the spaces in which this sector of

\footnotetext{
${ }^{1}$ Doctorando en Ciencias Antropológicas y Profesor Asistente, Cátedra Antropologia Social y Cultural, Universidad Nacional de Córdoba, Córdoba, Argentina. E-mail:juanzeballos2000@yahoo.com.ar.

2 La villa, también llamada "villa miseria" y "villa de emergencia", es el conjunto de casas o casillas precarias o sumamente precarias, donde se aloja el sector más bajo del proletariado. Si bien existe cierta variedad en las condiciones de habitabilidad, por lo general no las reúnen o apenas las alcanzan. La villa es el equivalente argentino a la favela brasileña.

$3 \mathrm{El}$ concepto existencia degradada se refiere a un profundo rebajamiento de las condiciones en las cuales se desarrolla la vida. Alude a las condiciones que dificultan, deterioran, erosionan la vida, transformándola en mera supervivencia.

4 La noción diacrítico-estigma biologicista hace alusión a los rasgos físicos, a los cuales se les han asociado valoraciones despectivas e inferiorizantes. Ejemplo prototípico de ello lo constituye la tonalidad oscura de piel.
} 
working class lives -or lives badly-: the villas. After the field work can be concluded that the most impoverished bias of wage-eaning class, which is in material conditions of existence characterized by informality, job insecurity and unemployment, whose correlate are highly precarious residences, with irregular access, limited, and without access, to water, electricity and gas services, respectively, in overcrowded conditions and with location hazards, it is stigmatized and discriminated. Likewise, beyond recognition, of the perception of discriminatory practices by those discriminated against, both low estimation and discrimination have the functionality of legitimizing socially the miserable conditions of live to which this portion of the population is subject. In this work, part of results obtained in a doctorate research is presented, which has as is theme the degraded existence ${ }^{5}$ and the diacriticbiologicist stigma ${ }^{6}$ in the city of Cordoba, Argentina.

Key words: working class, stigmatization, discrimination, biologicism.

\section{Condiciones materiales de existencia}

El Chaparral y Nueva Esperanza son dos villas de la ciudad de Córdoba, ubicadas en la zona norte de la misma, separadas una de otra por dos kilómetros aproximadamente -la segunda tiene la particularidad de ubicarse en parte dentro del ejido municipal de la ciudad de Córdoba, mientras que la otra porción pertenece a la municipalidad de Juárez Celman.

La génesis de estas villas, como la de tantas, remite a un proceso estructural de (gran) empobrecimiento de franjas del sector trabajador. Los asalariados inmersos en un marcado proceso de empobrecimiento, el cual se expresa -entre otros modos- en la ausencia de vivienda propia pero también en la incapacidad para afrontar el pago de un alquiler por largo tiempo, son quienes conforman las villas. Pero no se trata de nuevos asalariados empobrecidos. Los pobladores de ambas villas en su inmensa mayoria, son las víctimas de un proceso de pauperismo sufrido a lo largo de generaciones. Son hijos y nietos de trabajadores empobrecidos que moraban en otras villas o en barrios que no presentaban diferencias substanciales con relación a las villas, o en zonas rurales donde vivían en condiciones no muy distintas. Lo cual indica que los períodos en los que experimentaron mejorias económicas, éstas no fueron lo suficientemente profundas como para cambiarles de modo

\footnotetext{
5 The concept of degraged existente refers to a profound lowering of conditions in which the life develops. It alludes to the conditions that hinder, deteriorate, erode life, transforming it into mere survival.

6 The biologic diacritical-stigma notion refers to physical features, to which derogatory and inferiorizing evaluation, have been associated. A prototypical example of this is the dark skin tone.
} 
radical las condiciones de vida, al tiempo que no estuvieron acompañadas por programas estructurales y permanentes de acceso a la vivienda propia.

En otros términos, las villas conforman las residencias del escalón más bajo de la clase obrera, peldaño cuyos integrantes en ocasiones se convierten en desclasados dada la pérdida de la fuente laboral. Se trata de la "superpoblación relativa": "población obrera excesiva para las necesidades medias de explotación del capital, es decir, población obrera remanente o sobrante" (MARX, 2008, p. 533). Es la porción de población que alterna períodos de trabajo y desempleo, momentos estos últimos en los que desenvuelve cualquier actividad que esté a su alcance que reporte un ingreso económico que permita sobrevivir.

Esta superpoblación relativa es alternadamente de carácter, por un lado, "intermitente", ya que "forma parte del ejército en activo, pero con una base de trabajo muy irregular" (MARX, 2008, p. 544), y por el otro, "flotante" (MARX, 2008, p. 543), dado que luego de ser absorbida por la expansión de la demanda de trabajo es despedida cuando la misma decrece.

Durante los períodos ocupacionales, la situación laboral de esta fuerza de trabajo por lo general se asemeja a la siguiente descripción: "máxima jornada de trabajo y salario mínimo" (MARX, 2008, p. 545). Sin embargo, en algunos casos la jornada laboral es reducida aunque del mismo modo se reduce el ya depreciado sueldo. Con salarios por lo general sumamente bajos el "nivel de vida desciende por debajo del nivel normal medio de la clase obrera" (MARX, 2008, p. 544), ingresando plenamente a "la órbita del pauperismo" (MARX, 2008, p. 544), circunstancia que de manera palmaria se agudiza cada vez que alguna crisis económica asola al país. En definitiva, es una "masa de individuos sin medios estables de vida y que viven en la zozobra y en la desesperación” (FRONDIZI, 1954, p. 50), lo que la asemeja a la idea de "subproletariado" (SARTRE, 1968, p. 38). ${ }^{7}$

Con todo se debe indicar que estos trabajadores, a diferencia de la situación que analizaba Marx en Inglaterra, no se emplean en la rama

\footnotetext{
7 En la Argelia colonia francesa, es decir, país de explotación agrícola, el trabajador rural argelino para Sartre era un subproletario dado el salario insignificante que percibía por su fuerza laboral, lo cual lo condenaba a una existencia paupérrima.
} 
industrial propiamente dicha. Sino que se desenvuelven en labores de escasa calificación y que implican baja remuneración, al tiempo que comúnmente en condiciones de informalidad; sin la declaración ante el Estado. Lo cual no sólo implica un delito por evasión de parte de quien contrata sino también el avasallamiento de los derechos laborales contemplados en el contratado de trabajo. Que incluye hasta algo tan básico como la obra social. ${ }^{8}$ En tal sentido, durante el trabajo de campo, fueron frecuentes discursos tales como: "...son muy pocos los que dicen estamos en blanco en una empresa..."; “...son pocos los que tienen obra social...".

Esta fuerza de trabajo posee escasa calificación no sólo por la poca instrucción formal con que cuenta, de lo cual los siguientes extractos de relatos son indicativos: “...yo habré ido hasta quinto grado más o menos (escuela primaria) [...] pero sé todo, o sea lo que es escribir, leer, sumar, las cuentas..."; “...mi marido tiene hasta sexto grado. Y le cuesta leer. Yo tengo secundario completo..."10; "...yo no terminé el secundario, dejé a la mitad de sexto año...”; “... (Hice) hasta primer año (secundario) nomás [...] hice la (primaria) nocturna...”; “...yo hasta primer año...”, sino también por la exigua experiencia laboral que posee, la cual a su vez es producto del sistemático desempleo padecido. El desempleo además de generar para quien lo vive un presente dramático, terrible, tiene un efecto residual: impide o recorta la experiencia laboral, factor éste de suma importancia a la hora de conseguir empleo.

Los varones básicamente se emplean en el ramo de la construcción, mayoritariamente en la albañilería. Hacia el año 2014, cuando se iniciara la labor etnográfica, algunos trabajadores indicaron:

-“...laburo"11 en la construcción... Me llaman cuando tienen algo... Pero hay poco laburo. Trabajo para contratistas. Cuando te tienen te pagan por dia. Estoy en "negro".12 Pero no te pagan lo que corresponde... Acá

\footnotetext{
8 Las Obras Sociales son las instituciones o entidades cuya función es brindar cobertura médica a los trabajadores, para lo cual a los asalariados se les realiza un descuento mensual de su salario.

9 La expresión "estar en blanco", por oposición a "estar en negro", significa que el trabajador está debidamente declarado por parte del empleador al Estado. Es decir, el vínculo laboral está acreditado por quien contrata.

10 Este caso es prácticamente excepcional.

11 En Argentina laburar es el término comúnmente empleado para hacer referencia al acto de trabajar.

12 Trabajar en "negro" es una expresión ampliamente difundida en Argentina, que significa que no hay ningún tipo de vínculo formal en la contratación. La relación entre empleador y trabajador no está mediada por contrato alguno.
} 
a un oficial le están pagando 200-250 por dia [...] puedo sacar 4000 por mes pero a veces...”;

- "...trabajé en los countries, pero asi "re de negro"13 [...] era de Malvinas el hombre, ${ }^{14}$ el contratista, un "cagador", 15 después tenía ganas de mandarle un abogado que... [...] siempre en "negro" [...] empezamos de cero una casa en un country y después otra, después me cansé, laburábamos mucho y no quería subir (el pago) el chabón, ${ }^{16}$ después empecé a laburar en otra obra y me pagaban mucho más y eran muchas horas menos que este otro chabón..."

Por su parte las mujeres, cuando trabajan fuera del propio hogar, son absorbidas en la esfera de las labores de la "reproducción social" (MALLIMACI-BARRAL \& MAGLIANO, 2016, p. 85) principal y específicamente para el trabajo doméstico, el cual consiste en tareas de limpieza y afines, habitualmente con la modalidad "por hora". ${ }^{17}$ También hacia el año 2014 una de las entrevistadas afirmó: “...trabajo en casa de familia. No me va a creer, pero yo por dia estoy trayendo sesenta pesos, desde las ocho y media hasta las tres. Cobro 1200 pesos por mes...".

Cabe agregar que dentro del rubro de la "reproducción social", se incluye además el trabajo de cuidado de personas. Esta labor también constituye una fuente de trabajo para las mujeres de esta franja social: “...yo quedé sin trabajo. Cuidaba una nenita. Hace un mes que estoy sin trabajo. Era así nomás, de palabra. ${ }^{18}$ Ahora ando en el carro con mi mamá..."19 -en ocasiones el empleo involucra ambas labores: tanto el trabajo doméstico como el de cuidado personal.

\footnotetext{
13 La aseveración "re de negro" además de indicar la carencia de contrato laboral, señala centralmente una jornada laboral extensa con salario o jornal sumamente bajo. En la expresión se pone de manifiesto una analogía con el trabajo esclavo realizado por mano de obra proveniente de África. En Argentina es común el empleo de la manifestación: "trabajar como negro", la cual denota básicamente mucho o excesivo trabajo.

14 Malvinas Argentinas es una localidad cercana a la ciudad de Córdoba, dentro del Departamento Colón.

15 Estafador por no pagar lo que le correspondía.

16 Modismo de origen lunfardo que en sus inicios hacía referencia a una persona incauta, pero que en la actualidad denota simplemente hombre.

17 Se estipula una tarifa por hora y de acuerdo a la misma se paga según la cantidad de horas trabajadas.

18 Sin contrato alguno.

19 La última afirmación indica que junto a su madre y gracias a un carro tirado por un caballo, esta desocupada estaba sobreviviendo gracias a la recolección callejera de deshechos.
} 
Los varones también se emplean, aunque en similar condición de informalidad y sin elementos de cuidado, en "cortaderos de ladrillos", 20 en el mercado de abasto e incluso en fábrica de "pipas" de girasol21:

-“...laburamos en el cortadero de ladrillos. Yo cargo los camiones, (y) él está aprendiendo a cortar ladrillos... [...] Desde que dejé el colegio22 siempre trabajé en los cortaderos... [...] ahi se labura por tanto, te pagan por pila de ladrillos, por mil ladrillos te pagan 140 pesos [...] si me pongo las pilas hago mil en un dia....... ...cargo de a seis, ocho... te pagan 50 pesos cada mil que cargás...........los mil ladrillos los están vendiendo a ochocientos pesos [...] le queda bastante [diferencia]... Es una rata el patrón, no te quiere dar nada... ...el horario es de las 8 a las 12 y de las 2 hasta las 6 [...] de lunes a sábados... [...]...trabajamos con las manos, asi nomás... [...]...si no vas un día [el patrón] te saca al vuelo [te echa]... [...]...nos fuimos porque era muy cansador...";

- “... trabajo en el mercado de abasto, soy changarin, ${ }^{23}$ hace un año $y$ medio, o dos...Entro a las 11:30, 12:00 del medio día, hasta las siete de la tarde, por ahí seis y media según como esté el trabajo, de martes a viernes y los lunes madruguero de 02:00 hasta las 10:30, 11:00 de la mañana, póngale... Trabajo para el dueño del puesto, a la mañana le descargamos todo y a la tarde al que compra... estoy asi nomás [...] todos estamos "en negro" somos una bandita de chicos ${ }^{24}$ como ocho, nueve, [...] 250 pesos por día [...] me pagan encima por dia... [...] nos tenemos que dar maña ${ }^{25}$ para todo, para comprar, juntar monedita por monedita, yo traigo mucha verdura, también vendemos bolsas como para ir juntando, siempre traigo papas, cebollas, tomates, para comer $y$ para vender...";

- “...estoy laburando en una fábrica de "pipas" de girasol, de las siete de la mañana a la cinco de la tarde, nada más que ahora estamos haciendo hasta las tres porque se está vendiendo poco [...] de lunes a sábados, el sábado hasta las tres de la tarde [...] 1200, 1000 pesos por semana [...] estoy en negro, hace siete meses, desde que me fui del cortadero, y no me pone en blanco nada, y me dijo que a partir de tres meses me iban a poner en blanco, cumpli los tres meses sin faltar, y no pasa nada, salvo la vez que me tuvieron detenido..." 6

Asimismo, otras de las tareas a las que se dedican algunas trabajadoras son la confección de bolsas para leña y carbón, y la venta de cosméticos por catálogo.

\footnotetext{
20 Cortadero de ladrillo es el nombre dado al lugar donde se producen ladrillos. Si bien en la zona existían varios, lo cual constituía una fuente laboral que absorbía gran parte de la población de El Chaparral, en la actualidad solamente resisten a la crisis un par de ellos.

${ }^{21}$ Pequeña fábrica donde se tuesta, salan y empaquetan las semillas de girasol para su consumo. La denominación "pipas" proviene del nombre de una de las marcas registradas dedicadas al rubro.

22 Este joven abandonó la escuela secundaria en segundo año.

${ }^{23}$ Changarín es quien se dedica a cargar y descargar las mercaderías.

24 Grupo de jóvenes.

25 Ingeniárselas.

${ }^{26}$ Este joven asalariado fue detenido una noche cuando salió de su trabajo momentáneamente y se dirigió a un kiosco cercano para realizar una carga virtual a su teléfono celular, siendo que el argumento de la detención fue averiguación de antecedentes penales. Estuvo detenido dos días hasta que fue liberado por no haber pedido de captura ni antecedentes delictivos.
} 
En los períodos de desempleo sobreviven gracias a las "changas" y al "cirujeo", incluso apelan a la mendicidad. En realidad puede afirmarse que subsisten gracias a la combinación en diferentes medidas de estas tres actividades.

Las "changas" son labores de cualquier tipo aunque de escasa calificación y temporarias que se pueden realizar en uno o pocos dias, y que involucran a uno o pocos trabajadores. Trabajos en albañilería, desmonte y corte de leña para la posterior venta (estimulada por la presencia de descampados cercanos) son las "changas" usuales.

El "cirujeo", por su parte, hace referencia a la recolección callejera de elementos desechados que luego serán comercializados. Cartón, papel, vidrio, metal es lo más buscado, aunque cualquier objeto que pueda ser vendido, inclusive reutilizado, es recolectado y acarreado de la calle. Quienes realizan esta tarea también son nombrados como "cartoneros". Precisamente por uno de los elementos que colectan. Para ello construyen carros que pueden ser tirados por caballos, por motos pequeñas o por los propios trabajadores. Frente a la desesperación de no tener otro medio para sobrevivir, la recolección de diversos tipos de residuos es uno de los últimos recursos a los que se recurre. Más aún, dada la no inserción laboral crónica muchos de los pobladores de estas villas, se dedicaron únicamente o durante gran parte de sus vidas al "cirujeo". Y hasta en algunos casos los basurales $^{27}$ fueron la fuente de ingresos y de comida durante gran parte de sus vidas, sino la única o central.

Emparentada con el "cirujeo" se encuentra la mendicidad. Algunos de estos individuos desclasados reconocieron que para poder alimentarse y alimentar a sus hijos, tuvieron que "salir a pedir" a carnicerías, panaderías y verdulerias. La mendicidad es otra acción a la que se echa mano en una circunstancia tan crítica como la del desempleo. Algunos relatos dan cuenta de tales circunstancias:

\section{-“...junto latas, botellas y cartones toda la semana para hacer doscientos pesos. ¡Hay que andar para juntar doscientos pesos! Hay semanas que no hay nada...";}

\footnotetext{
27 Basural es el sitio donde se arrojan y acumulan residuos (basura), los cuales pueden ser orgánicos, inorgánicos, incluso hospitalarios.
} 
-“...nos pasó una vez cuando estábamos viviendo en Malvinas que tuvimos que salir a cirujear porque me quedé sin trabajo y andábamos por todos lados... [...]...todos los dias estábamos metidos en el basural, [...] vidrio, chapa, cartón, todo, hasta pa' comer sacábamos ¿vio? porque tiraban de todo y estábamos todo el día. Íbamos todas las tardes, de 6 en adelante cuando ellos se iban [quienes descargaban la basura]... Por ahí nos agarraba la noche y teníamos que estar con la linterna en medio de la mugre "cirujeando" siempre tuvimos un suertón [mucha suerte], siempre encontrábamos cosas. Metal para vender, aluminio ¿vio? [...] fue hace poco, antes de venir para acá [...] varios meses [...] tiraban de los supermercados... yogur... [...] nunca tuvimos nada por comer lo que encontrábamos... [...] gracias al basural nos pudimos comprar una motito, me acuerdo ¿vio?, íbamos pagando de a poquito e íbamos todos los días en la moto y teníamos un carrito [...] la buscaba a ella y nos íbamos y así todos los días. Ya nos habiamos como acostumbrado [...] ir a ver qué encontrábamos [...] yo chocho [contento] estaba porque encontrábamos... [...]...a nosotros nos daba de todo el basural, encontrábamos de todo, todo vendiamos nosotros... $\left[\right.$...]...si nos quedábamos aplastados ${ }^{28}$ nos cagábamos de hambre ${ }^{29}$ todos y ayer empezamos a salir de vuelta (a "cirujear"), no nos queda otra... [...] [Sin carro] con las manos, nos venimos caminando del centro hasta el hospital infantil y después tomamos el colectivo...";

-“...y por ahi se come la "huesada" queda otra. En una carnicería nos dan un par de huesos, si van con carne mejor, pero bueno..."

Otra labor económica que se registró, es la venta ambulante/callejera de alfajores y pan casero de elaboración propia. También se conoció el caso de un desempleado que cuenta con un automóvil propio, gracias al cual trabaja como remisero aunque de manera clandestina y/o irregular. Se trata de una actividad económica "indenunciable" (WACQUANT, 2010, p. 61) aunque obviamente no delictiva:

“...yo me la rebusco con otras cosas: con el auto, (ya que) somos siete... [...]...no estoy legalizado y ellos [la municipalidad] no entienden en la situación en que estás... [...]...al centro [de la ciudad] muchas veces no voy por el tema del control, me llegan agarrar los controles me llevan con auto y todo... [...]...con el remis no sé si llego a 3500 pesos por mes..."

En sintesis, desempleo y salarios o ingresos ampliamente insuficientes para atender las necesidades básicas, constituyen la base material del polo social desfavorecido por las contradicciones económicas.

\footnotetext{
28 Sin hacer nada, en pasividad. La expresión se vincula con el hecho de quedarse en la cama, acostado.

29 Pasar hambre, sin comer o sin comer lo suficiente.

30 Los huesos de vacunos pedidos a alguna carnicería.
} 
Y el correlato habitacional de ello es la villa. En El Chaparral y en Nueva Esperanza, las viviendas en muchos casos no reúnen condiciones minimas de habitabilidad, mientras que en otros apenas las alcanzan. Si bien la mayoría de las casas tienen paredes de ladrillos, también se registraron paredes de barro, aunque unas y otras en su inmensa mayoría sin revocar. Asimismo, en algunos casos las habitaciones son de chapas, cartón y/o madera. Todas tienen techos de chapas de zinc, y para lograr cierta aislación térmica en algunos casos se suelen colocar planchas de telgopor. ${ }^{31}$ Sin embargo, la aislación lograda es sumamente insuficiente y las viviendas poco pueden hacer frente al calor y al frío. Incluso en no pocas oportunidades, el agua de la lluvia también ingresa debido a las frecuentes roturas de las chapas. Generalmente el piso es de cemento, aunque en ocasiones es de tierra. La cantidad de dormitorios suele ser insuficiente dada la cantidad de moradores, al igual que el número de camas. En este sentido, es habitual que dos o más personas compartan la misma cama. El hacinamiento es una situación normal. Así también, resulta común que los baños sean simplemente letrinas.

Con relación a los servicios, la situación es variada aunque deficitaria. El acceso al agua es irregular e insuficiente, aunque no cobrado por la empresa privada que vende el servicio, ya que ambas villas mediante la autogestión se conectaron a un "caño maestro" que abastece el líquido a los barrios linderos. Si bien en ambas villas la cantidad de agua que llega es escasa, en Nueva Esperanza la situación es más crítica lo que genera que sus habitantes también consuman agua no potable, la cual acarrean en baldes desde un campo de cultivo ubicado en las cercanías. Dicha agua es usada para el riego del campo y el dueño del mismo les permite el acceso para aprovisionarse del vital elemento.

Por su parte, el suministro de energía eléctrica domiciliaria se realiza mediante "limitadores de carga", por los cuales se paga una "tarifa social". Esto es, el consumo energético está restringido por la capacidad de un

\footnotetext{
31 Telgopor es el nombre comúnmente dado al material poliestireno expandido. La utilización de la palabra obedece a la identificación que se produjo entre el nombre de la empresa que lo fabricaba originalmente y el material en cuestión.
} 
transformador domiciliario. Cuando éste llega al límite, el dispositivo interrumpe el abastecimiento hasta que se enfrie, luego de lo cual permitirá nuevamente el suministro. No existe red de gas, por lo tanto para cocinar algunas familias utilizan gas envasado mientras que otras emplean leña recolectada, incluso cualquier elemento de madera que pueda ser quemado; puede que la misma familia alternativamente utilice las dos posibilidades para cocinar. La calefacción hogareña para los días fríos se realiza mediante leña. En una de las recorridas a Nueva Esperanza realizada en la época invernal, pudo observarse cómo una mujer de aproximadamente cincuenta y cinco años junto a una niña, acarreaban leña seca con el objetivo de calentar su precaria vivienda.

Tampoco hay cloacas, simplemente "pozos negros" (generalmente sin cámaras sépticas), que suelen llenarse y aflorar. El alumbrado público al interior de las villas es inexistente. Sólo cuentan con las lámparas domiciliarias colocadas al frente de las casas. No obstante, la recolección de residuos es frecuente. Ahora bien, a lo enumerado se le agrega lo que puede señalarse como un doble peligro de emplazamiento. Por un lado, en la zona donde se ubican ambas villas abundan los mallines. ${ }^{32}$ En tal sentido, son habituales las rajaduras de paredes e incluso el hundimiento de las casas o casillas. Por el otro, la gran cercanía de canales de riego y de desagüe de la autovía próxima, al tiempo que la falta de desagües, han propiciado que lluvias intensas generen la inundación de ambas villas.

De este modo, la vida de este sector de la clase obrera es por demás dura. Aún más, se trata de una existencia dificultada cualitativamente por las condiciones en las que se desenvuelve.

\section{La villa: objetivo de prácticas discriminatorias y valoraciones degradantes de clase. Implicancia}

Al cúmulo de objetivas condiciones de existencia de este sector obrero, tanto en lo estrictamente laboral como en su correlato habitacional, se le montan calificaciones. Se trata de subjetividades que se elaboran en otras clases sociales y en otros sectores de la clase trabajadora.

${ }^{32}$ La palabra alude a un suelo cuya característica es ser bajo e inundable. 
Pero estas valoraciones, por un lado, son marcadamente degradantes o estigmatizantes -la definición de estigma lo explicita como un "atributo profundamente desacreditador" (GOFFMAN, 2006, p. 13), considerando también atributos a factores que pueden ser definidos como circunstanciales tales como la nacionalidad, la religión y la situación económica, sin embargo, lo importante de la definición es la esencialización negativa, degradante que conlleva. En tal sentido, en el presente artículo los términos degradación y estigmatización son sinónimos y por lo tanto intercambiables. Y por el otro, no se circunscriben al o no permanecen en el fuero íntimo de quienes las poseen sino que son exteriorizadas, traduciéndose en prácticas discriminatorias que se ejecutan sobre los despreciados -en rigor, la estigmatización y la acción discriminatoria propiamente dicha en este caso, son caras de la misma moneda, van de la mano: toda práctica discriminatoria involucra degradación, mientras que ésta cuando se manifiesta en actos produce prácticas discriminatorias. ${ }^{33}$

Siguiendo al INADI ${ }^{34}$ la discriminación en términos genéricos "es una relación social, centrada en el posicionamiento identitario jerarquizado y por lo tanto desigual”. 35 En el caso específico de las prácticas de discriminación y de la estigmatización sobre esta porción de la clase trabajadora, quienes las ejecutan y ejercen en líneas generales se encuentran en un espacio social en mayor o menor medida superior, material y/o simbólicamente.

Sin embargo, no es una mera construcción identitaria sin más, sino que se ampara en, se debe a, y/o se corresponde con, una estructuración social vertical y con grandes grados de desigualdad material, en la que unas clases explotan a otras. Se trata de una manifestación de orden subjetivo que evidencia las objetivas, diferentes y superiores e inferiores posiciones sociales, enmarcadas en relaciones de explotación. Esto es, quien degradada y discrimina "recuerda" a su víctima el lugar inferior que ocupa y la estima que despierta por ello, al interior de una estructura social de clases

\footnotetext{
33 Esta relación también fue señalada (GOFFMAN, 2006).

34 Instituto Nacional contra la Discriminación, la Xenofobia y el Racismo.

35 MOURATIAN, Pedro. Documento temático INADI. Racismo [Online]. Hacia una Argentina intercultural. disponible en: http://inadi.gob.ar/wp-content/uploads/2013/05/RACISMO_web.pdf. Acceso en: 17/12/14.
} 
construida a partir del clivaje propiedad/no-propiedad de los medios de producción, aunque sin explicitar la condición de explotado.

En definitiva, en este caso lo que se discrimina y estigmatiza es la porción más baja de la clase explotada, empleando como motivo aparente o formal el hecho de habitar una villa, evitando de esta manera aludir precisamente a dicha condición de clase.

De este modo, el lugar y las condiciones de residencia se convierten en causas valederas para discriminar y degradar -se trata de, por un lado, un "poderoso estigma asociado a la residencia en los espacios restringidos y segregados" (WACQUANT, 2010, p. 129), y por el otro, que la "pobreza" se erige en causa de la "violencia discriminatoria" (KAUFMAN, 2012, p. 31). Todo ello deriva en una situación claramente perversa: las víctimas son responsabilizadas por la situación que atraviesan sin más.

Ello apunta a obturar el reconocimiento de la villa en tanto consecuencia o manifestación estructural de la contradicción económica llevada a ciertos grados, pergeñándola, más bien como "el problema", o como un problema que de ningún modo se vincula con las relaciones sociales de producción.

Lo primero que pudo registrarse en los diálogos fue que, en términos generales, quienes habitan tales lugares por el mero hecho de hacerlo, se saben, se reconocen tratados de una manera diferencialmente negativa con relación a los miembros de otras clases sociales y de otros sectores de la clase trabajadora. Asimismo, para dar cuenta de este trato recurren al término discriminación y sus derivados; no se expresan mediante los conceptos de degradación y estigmatización: “...me hace sentir mal que te apunten por vivir en el fondo [en la villa]...”; “...la otra gente, la de adelante [la del barrio] nos pusieron Ciudad Oculta porque dicen que estamos ocultados de todo...”; “...más que por ser morocho, la discriminación viene por dónde vivimos..."

De estas expresiones se puede extraer otro par de conclusiones. Quienes estigmatizan son otros trabajadores aunque un tanto mejor posicionados materialmente. No obstante, en ocasiones las diferencias con 
los habitantes de las villas no son tan marcadas. En tal sentido, los últimos dos discursos transcriptos fueron pronunciados por moradores de Nueva Esperanza, y hacen alusión a habitantes del barrio lindero Alicia Risler, el cual ostensiblemente está conformado también por un sector empobrecido de la clase asalariada. Trabajadores de dicho barrio expresaron su desprecio y rechazo "bautizando" al lugar de residencia de otros trabajadores aún más empobrecidos de manera peyorativa. Evitando el nombre que se dieron a sí mismos, los motejaron negativamente. Les adjudicaron una "identidad" a partir de la burla -reeditando el nombre de una villa de la ciudad de Buenos Aires- en la que se conjugan de algún modo humillación y ofensa, por el mero hecho de vivir en condiciones paupérrimas.

Se debe señalar también que en los diversos testimonios tanto de varones como de mujeres, las manifestaciones degradantes o, en palabras de sus víctimas, discriminatorias se reducen, se circunscriben, se deben específicamente al lugar de residencia: vivir en una villa, y no a cuestiones, por un lado, de género (en el caso de la mujeres), ni por el otro, físicas (diacrítico-estigma biologicista: "por ser morochos"). Es posible que ello se deba al lugar que ocupen estas otras causas de degradación en sus vidas. Es decir, un espacio netamente subalterno, marginal, secundario en comparación con lo que consideran preponderante o central. En otros términos, es posible que sufran o hayan sufrido degradación tanto por género, en el caso de las mujeres, como por la dimensión física, en el caso de quienes poseen características físicas tales como piel oscura, sin embargo, las mismas no fueron o son percibidas como graves ya que no adquieren la dimensión de las calificaciones que involucra vivir en una villa.

\section{Sensaciones, estereotipos y estrategias}

Algunos pobladores accedieron, o más precisamente se atrevieron, a expresar sus experiencias respecto de situaciones de discriminación:

\footnotetext{
- “...más que todo a mi me da vergüenza porque a mí me llevan y me traen del hospital, el problema siempre fue porque yo vivo acá. Encima vivo al fondo de la villa (y) se les complica llegar, entonces antes un tiempo, más de un año tenía que cruzar de acá para la ruta, porque me esperaba ahí, en la ruta, porque no entraba para acá el remis, porque la villa, el miedo a que te pase algo [...] aunque nunca, nunca, nunca le pasó nada.
} 
Después cambiaron de gente, cambiaron de empresa en el hospital y hasta ahora José [el chofer del remis] nunca tuvo problema en entrar y buscarme hasta acá [...] es como dice, todo depende de cada uno [...] pero eso siempre fue una vergüenza, el hecho de vivir acá como que te miran "uh, la villera", si te tratan raro a veces te preguntan en el hospital: "¿Dónde vivis?, ¿En El Chaparral? y ¿Dónde queda?" [...] y siempre te preguntan: $y$ "¿Andan a los tiros?". Por ahi evito dar la dirección de acá y le doy la dirección del barrio de mi mamá; donde voy doy la dirección de mi mamá para que no me miren mal [...] tampoco para sentirme mal yo, porque decirles vivo en la villa tal... [...] es asi [...] mi marido por ejemplo, no tiene la dirección de acá, él hizo el documento [...] puso la dirección del tío [...] porque el hecho de vivir acá no lo tomen [para trabajar]...";

-“...Te pasa... en el banco, por ejemplo. Tenía que sacar la tarjeta para cobrar y me pedian un impuesto. Yo le decía: "קPapi, ${ }^{36}$ no tengo, vivo en una villa!" Yo llevaba todos los papeles y me daban vueltas. De ahí me mandaban al seguro. ${ }^{37}$ Me harté y les dije a los de la empresa que me pedian otras cosas. Ellos hablaron y listo... iTe tenés que acercar a la ventanilla y decirle en voz baja:" vivo en El Chaparral!" Yo digo que vivo en Guiñazú, no digo El Chaparral. Te sentís... vivo en una villa, pero no por eso soy choro, ${ }^{38}$ y asi un montón... Y bueno, le dije a mi viejo "dame una boleta de luz" (para "constatar" el domicilio)... Te sentís discriminado... O cuando tomaba un remis y le decias "hasta El Chaparral"... No, te contestaban, "yo te dejo a la orilla de la ruta"..."; - "...la otra vuelta fui al hospital por los chicos y tomamos un remis para volver y nos dejaron en la ruta porque no se quieren meter para acá; si no son conocidos que andan por acá no se meten [...] cuando dejás un curriculum para un trabajo yo les sé dejar la dirección de mi mamá...”

Lo problemático de vivir en una villa -al margen de las sucintamente señaladas condiciones, entre otras-, de cara al resto de la sociedad puede reconocerse a partir de los denominadores comunes que presentan los anteriores discursos. Estos elementos compartidos que se relacionan estrechamente son tres y pueden resumirse como: la sensación que manifiestan tener quienes sufren las acciones discriminatorias, los elementos que se emplean en tales prácticas y una estrategia para sortearlas.

En primer lugar, los discriminados manifestaron experimentar lisa y llanamente vergüenza frente a la situación de ser reconocidos públicamente -fuera del ámbito propio- como moradores de una villa, lo cual implica necesariamente el conocimiento (que no debe confundirse con aceptación ni

\footnotetext{
36 Diminutivo de papá. Papí, papá son expresiones coloquiales de sesgo cariñoso, afectivo, empleadas a Argentina en general, y en la provincia de Córdoba en particular. Cuando se la emplea sobre un desconocido, como en el caso en cuestión, dada la connotación positiva que goza pretende establecer cercanía, confianza.

37 Aseguradora de Riesgo de Trabajo (A. R. T.).

38 Chorro en Argentina es el término vulgarmente empleado para hacer referencia al ladrón. En la provincia de Córdoba la palabra es pronunciada con la consonante $r$ [choro], y no con doble $r$ [chorro] como es el caso de otras provincias.
} 
consentimiento) de las connotaciones que, sobre quienes las habitan se han construido y que circulan en el imaginario social. Este sentimiento vergonzoso también se manifiesta en el comportamiento de los hijos adolescentes de un poblador de El Chaparral: “... a veces ellos tienen amigos de otros lados y se sienten incómodos de traerlos..."

Pero no se trata simple o únicamente de tener vergüenza por las connotaciones que se derivan de vivir en una villa, sino también por las mismísimas condiciones en las que la existencia se desenvuelve en virtud de lo que ellas manifiestan en una sociedad de clases. Es decir, el sentimiento vergonzoso también obedece a la posibilidad de exponer las circunstancias en que sobreviven, tanto por las circunstancias en sí mismas como también por las diferencias, por la desigualdad, ya que saben perfectamente que otros sectores de la clase obrera y otras clases sociales no viven en tales condiciones.

En segundo lugar, las connotaciones negativas que pesan sobre este sector de la clase trabajadora por residir en villas se encuentran estereotipadas. Algunos de los estereotipos se expresan en las imágenes construidas de vagos, delincuentes y violentos: “...dicen ${ }^{39}$ que en la villa todos son vagos, que roban...”; “...pero como está ahora la ola de robos, lo primero que te dicen: son los nuevos, ${ }^{40}$ y siguen siendo los mismos de siempre..." 41

Si bien es cierto que determinadas modalidades de delincuencia y de violencia están indudable e innegablemente presentes en estas villas, y se vinculan con las mismísimas condiciones materiales de existencia en tanto condiciones de posibilidad, lo cual a su vez indica cierta base para la construcción de estereotipos, también es indudable e innegable que el relacionamiento expresa claramente una exageración, una generalización o, en términos literarios una sinécdoque: la identificación del todo con la parte. Más aún, son también los propios residentes en las villas lo que sufren también la delincuencia y violencia que otros de sus habitantes desarrollan.

\footnotetext{
39 Haciendo referencia a la policía y a los habitantes de barrios cercanos.

40 Quienes van poblando la villa.

41 Algunos habitantes del barrio limitrofe.
} 
Otro de los estereotipos es el supuesto consumidor irracional, desenfrenado, con prioridades opuestas a la satisfacción de las necesidades básicas. Una de las informantes clave de El Chaparral contó la situación vivida en el dispensario de la zona, por otra habitante de la villa:

\begin{abstract}
“... "imamá! ¡Este nene está desnutrido!, falta de olla es esto, a ver si dejamos los puchos y compramos para comer". "Discúlpeme pero yo no fumo", le dijo ella, "y a veces no tengo para darle todos los días de comer"... Tampoco es para que un doctor se dirija asi. Ahi viene también la discriminación... [...]...ese también es el tema, te preguntan: "¿de dónde sos?", "¿de la villa?", y ya te discriminan... No le digás que sos de El chaparral... Ellos mismos nos discriminan sin saber [...] porque somos de la villa..."
\end{abstract}

En este caso a priori se atribuyó la desnutrición a una aparente malversación de los escasos, insuficientes ingresos, producto de la orientación de los mismos a la satisfacción de un vicio/enfermedad. Otro de los clichés, otra sinécdoque. En la acusación se transparenta la idea de pautas de consumo económicamente insensatas, especialmente a los ojos de otros sectores de la clase asalariada y/o de otras clases sociales.

Por último y en función del objetivo laboral, se constató la estrategia de ocultamiento del domicilio real, fijando un domicilio formal por fuera de la villa. Generalmente se trata de la dirección de un familiar de confianza. Es común que a sabiendas de las connotaciones y generalizaciones que giran en torno a los habitantes de las villas, las cuales en gran medida pueden hacer sencillamente improbable la obtención del puesto de trabajo necesitado, sus habitantes brinden un domicilio en un barrio. Se trata de una estrategia de supervivencia, la cual es transparentemente "situacionista", ya que no pretende modificar nada, sino más bien sobrevivir en las condiciones imperantes.

\title{
Accionar estatal
}

Para esta parte de la clase trabajadora existe otra modalidad de discriminación. Fueron ellos mismos quienes se encargaron de ir un paso más allá, señalando que, por un lado, la discriminación puede ser pensada en términos ampliados, y por el otro, en quién recaería la responsabilidad por la misma. En tal dirección, las condiciones de vida en las que se encuentran constituyen en sí mismas un gran acto de discriminación, al 
tiempo que el mantenimiento o la no modificación en modo substancial de tales condiciones es competencia de los gobiernos. En este último caso, si bien no responsabilizaron explícitamente a los gobiernos como causantes de las circunstancias en las que se encuentran, sí lo hicieron por no erradicarlas, por no socorrerlos suficientemente. Por lo tanto, se trata de una responsabilización contradictoria. Asimismo, aunque se expresaron en términos de gobiernos y no de Estado, por la dimensión de la problemática se trata de un reclamo al Estado. En este sentido se transcriben parte de algunos relatos recogidos:

- "... y cada vez que yo no tengo agua es una manera de discriminación [...] por eso yo me siento mal porque la vez que tengo que ir acarreando agua es todo un sacrificio, como una burra...";

- “...yo pienso que la discriminación está entre todos, si vos te ponés a ver [...] hay muchas cosas de discriminación, si vamos a lo de acá todos estamos obligados a vivir así, por más que trabaje, te suben todo...";

-“...nosotros tuvimos una reunión, fuimos a plantearle todo esto a la intendenta [de Juárez Celman] y primero que se hizo negar que estaba, después nos hicieron entrar a tres para el problema de todos y se reían en la cara ella, después vino acá a una reunión [...] y dijo que iba a arreglar todo. [...] fue como que nos dejó de lado; Ella nos dijo que nosotros no perteneciamos a la municipalidad y que nosotros nos habiamos metido [...] porque ella que no, que no, porque no pertenecemos, porque tiene miedo que le hagan un juicio [de Vialidad Nacional] por eso no se quiere meter...";

-“...vinieron miles de personas [del gobierno] que pum, que pam, que bueno, que hacemos relevamientos, que van a ver, que los llevamos [a un barrio], que esto... Y acá lo mismo estamos...";

-“...los politicos vienen cuando necesitan los votos [...] todos tienen el informe [de la Junta de Participación Ciudadana] y no hacen nada..."

En esta línea, gracias a los diálogos fue posible detectar otra acción o más precisamente cierta omisión, que a los ojos de estos trabajadores también constituiría discriminación por parte del Estado. Una vecina de E1 Chaparral indicó: “...nosotros somos arbolitos... En los planos ${ }^{42}$ figuramos como arbolitos, como espacio verde, eso es discriminación, por la pobreza..." La denuncia muestra con ironía lo que consideran un ocultamiento sufrido y de algún modo también resistido.

42 Planos de la Dirección de Catastro de la Provincia de Córdoba. 
Si bien a los espacios que no han sido urbanizados en muchas oportunidades se los representa mediante el dibujo de flora, más precisamente árboles, el hecho de que se sepa fehacientemente de la existencia de El Chaparral -como de tantas, sino de todas las villas de la ciudad de Córdoba- que por lo demás data de bastante tiempo, por parte de los Estados provincial y municipal, habilita que se pueda afirmar que esta forma de representación del espacio de alguna manera es simultáneamente una forma de invisibilización. En los planos la naturaleza es empleada para ocultar la presencia humana. Se trata de una no-existencia formal.

Asimismo, en el sistema de ambulancias que atiende emergencias también se manifiesta cierto desprecio por la vida de quienes residen en villas:

-“...vos llamás a la ambulancia y necesitás que la ambulancia entre [...]
porque acá no entran porque la villa, porque esto otro...”;
“...mi marido se ahorcó ahí. Yo llamé a la ambulancia y nunca vino. Él
se terminó muriendo por eso, porque cuando lo encontré logré
reanimarlo pero no pudo recuperarse...”

No se puede saber si esta persona se hubiera recuperado con el auxilio de la ambulancia, pero lo que parece ser cierto es que aquella nunca acudió al llamado. Más allá del probable desborde o insuficiencia del servicio de ambulancias y frente al temor que involucra la villa por los eventuales asaltos, los trabajadores del servicio, y al igual que taxistas y remiseros, en ocasiones deciden no concurrir a las llamadas priorizando otras demandas. Con los agravantes de que se trata, por una parte, de la salud de las personas, y por la otra, de un servicio dependiente del Estado (municipal y provincial).

\section{Ponderación degradante}

También fue posible colectar alocuciones particularmente estigmatizantes que se ejecutan sobre este sector de la clase trabajadora.

En ocasión de una de las recorridas por El Chaparral se pudo registrar casualmente un operativo ordenado por la Empresa Provincial de Energía de Córdoba (E.P.E.C.), de desconexión de los denominados "ganchos", conexiones ilegales y precarias a los cables de baja tensión cuyo objetivo es 
el aprovisionamiento de energía eléctrica sin pagar por el servicio. El operativo fue llevado a cabo por la empresa Conectar y contó con apoyo policial, ya que esta clase de operativos por lo general despierta la resistencia de quienes están conectados de este modo. No obstante, el operativo tuvo otro objetivo. Aquellos hogares conectados mediante "ganchos", pasarian a ser beneficiarios del suministro mediante "limitadores de carga". Luego de que los "desenganchados" edificaran el pilar para la instalar la conexión regular, se implementaría el dispositivo.

Sin embargo, este segundo objetivo del operativo no fue indicado inicialmente a una familia que sufrió la desconexión y uno de sus miembros, un joven de aproximadamente veinte años, comenzó un reclamo airado. Frente a ello, uno de los operarios de Conectar, dirigiéndose a sus compañeros de cuadrilla y buscando la complicidad de los mismos, dijo: “...A ese mugriento hay que tirarle con un jabón... ¿Sabés lo que pasa?... es que a esta gente se le da demasiados privilegios..." La expresión insultante tuvo el volumen necesario tanto para ser oída por quienes estaban al lado de este trabajador, como para no ser escuchada ni por el aludido, el cual estaba siendo atendido por personal administrativo y vigilado de cerca por un policía, ni por otros habitantes de la villa que habian salido de sus casas para presenciar el operativo.

La consideración "mugriento" tiene dos condiciones de posibilidad vinculadas. Por un lado, la asimilación del trabajador pauperizado o sumamente pauperizado, a la suciedad que involucran las labores de escasa calificación y físicas. La suciedad de las ropas y/o del cuerpo denuncian las características de la ocupación. Los trabajos manuales y de escasa calificación, presentan valoraciones bajas las cuales se trasladan a quienes las realizan. De esta conjunción surge que la grasa, la porquería, la mugre, etc. con toda su carga despectiva y denigrante pasan a ser maneras alternativas de señalar, de nombrar a estos trabajadores. Y por el otro, la basura que abunda en la villa la cual en no poca medida es responsabilidad de sus habitantes. 
De manera conjunta o alternativa por cualquiera de las dos vías, "mugriento" especifica una modalidad degradante para referenciar a los sectores más depreciados de la clase asalariada, modalidad que señala inequívocamente la valoración que despierta para gran parte de la sociedad, este sector asalariado.

Asimismo, en la alocución se expresan dos dimensiones que se articulan. Por una parte, la esfera politica propiamente dicha puesta de manifiesto en la aseveración final. El pretendido privilegio contra el cual este trabajador despotricaba era la modalidad de tarifa social de electricidad mediante el sistema de "limitadores de carga". Al parecer, para este trabajador los paliativos que reciben los asalariados en peores condiciones son privilegios y abundantes. Se trata básicamente de un conservadorismo social, que pregona la menor ayuda estatal posible a las capas sociales más bajas. Por la otra, la esfera que aunque no deja de ser politica es más bien o puede ser considerada "técnica" o "instrumental". La degradación funciona como mecanismo de deslegitimación de reclamos y derechos. Dada la posición social subalterna, las reivindicaciones del sector son desacreditadas mediante la degradación. Ésta deviene en motivo o razón tanto de la posición social subalterna y de lo que envuelve tal posición, como también de la no mejora de la situación. En similar dirección se inscribe el relato de una de las informantes clave de Nueva Esperanza:

“..el lunes vino un vecino ${ }^{43}$ que lo tengo acá atrás por una pelota. Me
vino, me insultó y me dijo: "ustedes no son gente... [...]... ustedes se
tienen que ir todos de acá". Y en el solo hecho de que los vecinos podan
y tiran toda la basura para acá también es una forma de
discriminarnos, porque vos vivís ahí..........la gente [del barrio], ellos
pasan a ser normal, nosotros no... [...] todo lo que pueden, lo que no le
sirva, vienen y lo descargan para este lado, [...] ellos no nos respetan,
ellos nos ven a nosotros como unos villeros..."

Lo importante de este relato no es la indudable disputa en sí misma, sino los factores que se ponen de manifiesto en el discurso que la evidencia. Se trata de tres elementos relacionados: la negación de humanidad, el deseo de expulsión, y la anormalidad.

43 Habitante del barrio Alicia Risler. 
La negación de humanidad aunque fue formulada de modo absoluto en realidad no es total, sino más bien parcial. Esto es, el "no-ser gente", es reducir humanidad. "No-ser gente" es no-serlo plenamente, es no-ser en la misma medida que quien tácitamente presume de serlo. La insultante acusación degrada a la víctima, le quita valía y la ubica por debajo de quien así la rotula. Se trata de un rebajamiento de la condición humana, una inferiorización.

La pretensión de expulsión, por su parte, denuncia concretamente tanto relaciones problemáticas, como también el deseo de exclusión territorial de todo lo que involucra la villa. La villa es pensada como un espacio viciado, enfermo, manchado, en el cual moran las no-plenamente personas, y del que es prioritario y necesario alejarse lo más que se pueda para no ser contaminado, contagiado. La separación física es crucial para evitar el contacto y cuando ella no puede lograrse, se exacerba el deseo de exclusión, apelando a una supuesta incompatibilidad de orden cualitativo. Cuando las barreras físicas no existen, o debido a ello, se construyen, se insuflan las invisibles. Tanto la negación de humanidad como la pretensión de expulsión al haber sido proferidas por otro trabajador con quien las diferencias materiales no son tan pronunciadas, expresan la necesidad de separarse, de establecer distancias cuanto menos figuradas.

Mientras que el prácticamente explícito -por deducción- concepto de anormalidad es sumamente sugerente, un hallazgo, o más precisamente una muestra de lucidez de lo que significa socialmente vivir en una villa, tanto por las condiciones a las que se somete la existencia de quienes la habitan como por las subjetividades que despierta en otros sectores sociales. Las villas a pesar de estar socialmente naturalizadas -al igual que otras tantas situaciones degradantes-, en especial para quienes en ellas residen debido fundamentalmente, a la incapacidad de mejorar substancialmente su situación cuanto menos en un futuro cercano, no representan una situación de normalidad ya que escapan a ciertas condiciones también socialmente establecidas necesarias para el desarrollo sano, integral, etc. de la vida. La normalidad en este sentido, básicamente es residir en una casa con las 
condiciones apropiadas de habitabilidad y en un lugar en similar situación, circunstancias que no se dan ni en El Chaparral ni en Nueva Esperanza, pero que sus pobladores conocen en mayor o menor medida. De allí, pues, que estas villas expresan y materializan una "anomalía social" (WACQUANT, 2010, p. 129), están excluidas de la normalidad. Las condiciones en las que viven son anormales y por carácter transitivo los convierte también en anormales. No obstante, en líneas generales esta anomalía no es pensada como efecto sistémico sino más bien como producto de decisiones individuales. Eco de ello es el hecho que, de algún modo se sienten obligados a aclarar que vivir en una villa no es una elección: “...nosotros queremos dejar en claro que no nos gusta vivir así, no nos queda otra..."

Todos estos factores confluyen sobre quienes habitan estas villas. En esta dirección, la afirmación final: “...nos ven a nosotros como unos villeros”, si bien es posible que en alguna medida exprese el no-reconocimiento, la noaceptación, o más precisamente la negación de la propia realidad, manifiesta la degradación que encarna socialmente -para propios y extraños- residir en tal espacio, como el deseo de escapar del mismo. La expresión "villero" en términos generales -es decir, más allá de la resignificación positiva que los propios habitantes puedan construir o que de hecho construyen en ocasiones- es un insulto que señala la valoración estigmatizante correspondiente por vivir en tales circunstancias -confirmando ello, en ciertas oportunidades puede que tal expresión se emplee para degradar a personas que no viven en villas y a sabiendas de ello, atribuyéndoles las supuestas características de quienes las habitan, lo cual no hace más que confirmar la densidad del rebajamiento.

No obstante, es posible refinar aún más el análisis, ir incluso más allá de lo que la informante clave manifestó. El "villero" dejó de ser una persona que se encuentra inmersa en determinadas situaciones materiales, simbólicas, etc., para pasar a "ser" las circunstancias mismas en las que vive. Ya no es completamente un ser en circunstancias, sino las circunstancias mismas. La identidad propia le fue reemplazada por la negatividad que envuelven tanto las situaciones como las connotaciones del 
lugar en que se reside. La persona pasa a "ser" la totalidad degradante material y simbólicamente que conlleva la villa. El "villero" "es" la villa hecha persona.

$\mathrm{Ni}$ siquiera la pertenencia de clase permanece en pie. No hay trabajadores, en no pocas oportunidades desclasados, que viven (en muchos casos, sobreviven) en villas sino "villeros" a secas. O mejor dicho, quizás en un intento de solapar las responsabilidades que les caben a las clases dominantes, los explotados que fueron empujados a vivir en condiciones degradantes además de dejar de ser plenamente personas, dejaron de ser trabajadores.

Se trata de una noción, de una práctica determinista que apunta a aceptar, legitimar, o directamente naturalizar la situación presentándola como inevitable, lo cual en definitiva indica la imposibilidad sistémica para revertir radicalmente los procesos estructurales de empobrecimiento generados por la agudización de las contradicciones del modo de producción vigente.

\section{Estigma biologicista}

Ahora bien, existe otra expresión con similar intencionalidad y carga por demás usada. Se trata del término "negro".

\footnotetext{
"...A veces te dicen negro, vos te das cuenta por la forma. "iNegro de mierda!" Te están discriminando...”; “... [Nos dicen] "iLos negros del fondo!"...";

“...nosotros somos los negros de mierda, por vivir en el fondo. [...] Roban por aquel lado... ;Ah, los negros del fondo son!, jlos nuevos, los negros de mierda del fondo! [...] Todo para el fondo. Y son los del barrio, primos, sobrinos, $y$ después andan vendiendo las cosas..."
}

"Negro", al margen del sentido físico por el cual en Córdoba cuanto menos, apunta a quienes poseen cierto cromatismo amarronado en la piel, ${ }^{44}$ en este caso es un modo de referenciar a los sectores subalternos en general, y al interior de éstos a los más bajos en particular -por lo tanto se coincide con la aseveración: "funciona como significante englobador para la totalidad de las clases populares, cualquiera sean sus colores" (ADAMOVSKY, 2012,

\footnotetext{
${ }^{44}$ La acepción física de "negro" es una generalización que no explicita origen (por ejemplo, africano, americano, europeo del sur, etc.), simplemente apunta a cierta tonalidad oscura de la piel.
} 
pp. 354-355), aunque debe señalarse que este relacionamiento tiene como base cierta preponderancia que tienen al interior de estos sectores los cutis oscuros, a diferencia de lo que sucede en los sectores hegemónicos.

Este uso o sentido de "negro", más allá de que quienes padecen esta adjetivación peyorativa la consideren únicamente como una modalidad de discriminación, constituye indudablemente una práctica biologicista, ya que emplea las inferiorizantes valoraciones sociales que presenta el diacríticoestigma originalmente referido al esclavo africano: centralmente la piel oscura, para asignárselas o trasladárselas a las porciones subalternas de la población, degradándolas. Lo cual es coincidente con la afirmación: "las propiedades de los negros de las colonias fueron trasladadas a los sectores subalternos de las sociedades imperiales y también de los Estados Nacionales que se estaban configurando...” (BLÁZQUEZ, 2008, p. 14).

No obstante, quienes la emplean niegan que se trate de una práctica biologicista, pero no porque mientan u oculten sus acciones, sino más bien porque no lo consideran un acto de tal carácter -después de todo, el biologicismo al no ser percibido, menos aún puede ser reconocido. Ello también fue expuesto por otros autores: “...considerar a las relaciones sociales en términos raciales no aparece como una forma de racismo porque precisamente la calificación de negro no estaría determinada por el cromatismo tegumentario” (BLÁZQUEZ, 2008, p. 12) y “...quienes lo emplean suelen afirmar que sólo lo utilizan para referirse a las cualidades morales, intelectuales y gustos estéticos de quienes son así catalogados y que por lo tanto no estarían incurriendo en una forma de racismo" (FRIGERIO, 2009, p. 15). En síntesis, demuestra la internalización del diacrítico-estigma biologicista en particular y la naturalización del biologicismo en general. En el mejor de los casos, pueden llegar a reconocer que se trata solamente de un acto de discriminación por la condición social.

Se suele afirmar que "negro" nada tiene que ver con el color de piel, sino con los perfiles culturales. Esto es, con los gustos artísticos, los atuendos, las costumbres, pero también con el grado de instrucción alcanzado y las formas de comportarse inclusive moral y/o éticamente. 
En este sentido, en ocasiones se emplea la fórmula "negro de alma" que también fue indicado en el señalamiento: "negros, ya no "de piel" sino "de alma" (BLÁZQUEZ, 2008, p. 12). El análisis de la manifestación "negro de alma" es sumamente fecundo porque explicita lo que involucra este sentido de "negro".

Con el agregado "de alma", se pretende borrar la evidencia biologicista que se manifiesta en el término "negro" a secas. Es una especie de aclaración contradictoria o indicación de algún modo insostenible, que "el problema" no se encuentra en el color de la piel, sino en el comportamiento.

"Negro de alma" denota que toda la carga despectiva con que cuenta el diacrítico-estigma, se concentra ahora formalmente no en la dimensión física sino en la supuesta esencia del ser, y se transparenta o plasma en la dimensión cultural. Al esencializar las prácticas culturales éstas pasan a determinar las características de, y las valoraciones sobre, las personas. Sin embargo, las prácticas culturales, por una parte, a su vez están determinadas por aquella supuesta esencia inmodificable e incorpórea -el alma- y por la otra, son evaluadas o calificadas en función de un parámetro que continúa siendo el diacrítico-estigma "negro". Finalmente, aquella "esencia" termina soldada, ligada circularmente al diacrítico-estigma biologicista.

Es decir, a pesar que el núcleo duro de la degradación se ubica en la pretendida quintaesencia humana, el alma, al tiempo que se manifiesta transparentemente en las consideradas prácticas culturales despreciables que de algún modo abarca a la escasa instrucción alcanzada- y pautas de comportamiento censurables, se conserva la apelación al diacrítico-estigma "negro" en cuanto factor de calificación tanto de estas últimas, como también y explícitamente de la pretendida esencia responsable de las mismas, el alma. Lo cual indica que el diacrítico-estigma no únicamente es físico sino que también puede mutar parcialmente en entidad metafisica e interiorizarse. El diacrítico-estigma ha sido desatado de lo físico aunque sin abandonarlo, para adentrarse en los dominios del "espíritu", lo cual le permite desarrollar una acción ecuménica, incluyendo, englobando, 
conjuntamente con quienes lo portan -en su aspecto exterior-, a quienes no. De allí, pues, que una persona rubia y de ojos azules devenga en tan "negra" como quien exhiba el diacrítico-estigma.

"Negro de alma" o simplemente "negro" es la retórica que permite degradar profundamente, gracias a un determinismo exacerbado articulado o basado en tres pilares: las prácticas culturales, la aparente esencia espiritual y el biologicismo, aunque negando a éste último, a los miembros de los sectores subalternos en general, y especialmente al peldaño más bajo de la clase trabajadora, cada vez que se considere necesario manifestar tal desprecio, más allá de si responden o no al diacrítico-estigma de la piel oscura.

Sin embargo, aunque ser "negro" supuestamente se plasme o manifieste en las prácticas de orden cultural, no significa que sean éstas la razón de fondo para la degradación. No son las pautas culturales, ni las caracterizaciones intelectuales, psicológicas, morales, éticas y estéticas en sí mismas las generadoras de "negritud", sino el sector social que las desarrolla. O dicho de otra forma: se rechazan determinadas prácticas culturales en la medida que expresan o representan a la subalternidad social. El desprecio por el "Cuarteto" en términos genéricos -ritmo musical estrechamente vinculado con los sectores subalternos-, por ejemplo, de parte de los sectores hegemónicos no se debe tanto a las características rítmicas y/o poéticas, como por quienes son sus cultores prototípicos. La esfera cultural es la excusa, la formalidad, para una denigración cuyo carácter es de clase social. En rigor, "el problema" no está en las prácticas sino en quiénes las realizan.

El mismo acto ejecutado por miembros de los sectores hegemónicos no conlleva la adjetivación "negro", al tiempo que las prácticas propias de estos sectores por reprobables que sean o puedan ser, por lo general no son consideradas degradantes.

Si un habitante de una villa reclama por ser desconectado del servicio de energía eléctrica, que estaba robando, es "mugriento" y "negro" o 
manifiesta de este modo su "negritud", pero un empresario que también roba energía eléctrica, ya fuere en su casa o en su empresa, no lo es ni lo será.

De esta manera, si bien para las clases burguesas y pequeñoburguesas los miembros de sectores trabajadores en general y el escalón más bajo de la clase trabajadora en particular son "negros" en todo momento, cuando éstos últimos desarrollan algún comportamiento que es considerado no correspondiente con su específica ubicación social, la "negritud" es, más que activada, potenciada. No obstante, no únicamente las clases hegemónicas actúan de este modo. Incluso los trabajadores, como en el caso presentado y analizado del operario de la empresa que realizó la tarea de desconexión de "ganchos", exacerban el rebajamiento sobre otros trabajadores en peores condiciones como lo son los habitantes de las villas, cuando éstos últimos desenvuelven un accionar diferente al que se desea y espera en virtud del lugar que ocupan en la sociedad. En tales circunstancias la degradación se hace manifiesta, abierta, descarada.

\section{La estigmatización realizada por los degradados}

Pero los degradados en algunos casos también estigmatizan. En ocasiones las victimas sin dejar de serlo ser convierten en victimarios.

En momentos en los que se conversaba con un joven trabajador de El Chaparral, damnificado por el hundimiento de la cocina que estaba edificando debido a los mallines de la zona, éste fue saludado por otro morador de la villa que pasaba por el lugar, del siguiente modo:

“Hola boliviano!”, a lo cual el aludido respondió sonrientemente pero con algo de incomodidad: - ¡hola!”. Recién en ese instante se supo que con quien se conversaba era de origen boliviano. La forma no fue violenta. El saludo inicial involucró sonrisas al igual que la respuesta. En realidad se trató de una chanza entre amigos, una picardía con cierto grado de tolerancia por el vínculo entre ambos. Pero en la broma tolerada había algo. Por un lado, la nacionalidad boliviana era el chiste en si mismo, y por el otro, quien lo formuló se ubicaba en, y/o evidenciaba, una posición de supremacía con relación al referenciado. En una entrevista posterior con la compañera de este trabajador, la misma señaló: 
“...sí [lo discriminaban] los mismos compañeros de trabajo, porque él aspira a aprender, y no le gusta estar al vicio... Utilizan esa palabra [boliviano] [...] sí, varias veces ha venido bajoneado, ${ }^{45}$ ¿Por qué lo tratan así si él solo quiere trabajar? [...] los mismos compañeros, porque él siempre ha querido trabajar, porque eran medios vagos..."

No fue la única vez que el término boliviano se escuchó en estas villas. En una de las entrevistas en Nueva Esperanza, una trabajadora desarrolló un relato en el cual palmariamente expresaba su rechazo a los trabajadores provenientes de Bolivia:

“...hay muchas cosas de discriminación, ahora está prohibido (discriminar) [...] y yo pregunto: ¿Qué derechos tenemos nosotros en defendernos contra ellos?, mi marido trabaja, es peón de albañil, está puesto para ayudarle a un boliviano, lo insulta, lo trata de lo peor, de hijo de..., y si vos le llegás a decir: boliviano de mierda, pongalé, te van y te denuncian al INADI, ¿Y nosotros qué? Y el otro día mi marido le dijo: ¿iPero Qué!?;Si vos venís a nosotros a quitarnos el trabajo!, ¿Qué pasa si nosotros vamos a tu pais?... no, le dijo el otro, nosotros a ustedes no le permitimos... [...] ¿Qué defensa tenemos nosotros como argentinos contra ellos?, porque siempre está así... ¿Quién nos defiende a nosotros?..."

En Argentina en general y en Córdoba en particular, el término boliviano ha adquirido una connotación ostensiblemente peyorativa.

Probablemente en los dos últimos relatos, la competencia laboral al interior de este sector de la clase trabajadora sea la excusa o el disparador para el empleo de la expresión. No obstante, lo indiscutible es que se manifiesta en términos abiertamente xenófobos y solapadamente biologicistas. Es decir, se agravia y rechaza a trabajadores en iguales o peores situaciones materiales esgrimiendo la procedencia nacional, dando cuenta de cierta funcionalidad del pensamiento "anti-latinoamericano". Pero al mismo tiempo estos trabajadores en su inmensa mayoría portan rasgos físicos que remiten a los primeros pobladores de América, rasgos que en Argentina conforman un diacrítico-estigma. La mera posesión de tales rasgos genera la presunción de boliviano (e incluso de peruano).

De allí, pues, que en tanto insulto "boliviano" presenta dos esferas articuladas: la nacionalidad, la cual involucra estereotipos culturales, y las características físicas, cuya síntesis es el rechazo y desprecio por lo

45 Triste, dolido por el trato recibido de sus propios compañeros de trabajo. 
"latinoamericano". ${ }^{46}$ Ahora bien, estas esferas pueden ser empleadas de alguna manera por separado, o de algún modo eclipsando una a la otra dependiendo que quién las utilice. Esto es, la degradación puede apelar a la condición nacional o la dimensión física alternativa o predominantemente.

En principio, en los casos transcriptos se invocó la nacionalidad, ya que no se apuntaba a las particularidades corporales exteriores. Más aún, en el primero de los casos: quien saludara diciendo: - “.. ¡Hola boliviano!...”, posee una tonalidad de piel incluso más oscura que la del trabajador de origen boliviano aludido, algo frecuente en villas y barrios de trabajadores empobrecidos de Córdoba. Vale decir, la referencia a la pertenencia nacional desde una posición xenofóbica primó sobre las particularidades somáticas. ${ }^{47}$

Sin embargo, que durante la labor etnográfica en estas villas no se registraran referencias a la dimensión física propiamente dicha, no obtura ni impide reconocer que en Argentina en general, y en Córdoba en particular, quien ostenta rasgos de los primeros pobladores americanos es señalado despectivamente como boliviano, incluso a sabiendas de que es argentino.

Con todo, la utilización degradante de la expresión boliviano en una villa obedece al objetivo de establecer distancias cuanto menos simbólicas, ya que las materiales son inexistentes o prácticamente inexistentes, debido a que muchos bolivianos viven en villas y desarrollan los mismos trabajos aunque en muchos casos en peores condiciones.

Pero no se trata únicamente de explicitar distancias. Se trata de ubicar a otros asalariados en un plano inferior pretendiendo no ser el último escalón de la sociedad de clases. En este sentido, la xenofobia les ofrece lo que las relaciones sociales de producción les niegan. A la exclusión, a la marginación material y simbólica, el rechazo al trabajador inmigrante brinda

\footnotetext{
46 Habria una tercera dimensión que participa de la expresión "boliviano" en Argentina: la de clase social. Sin embargo, a los fines del presente trabajo queda fuera de análisis.

47 Desde esta perspectiva el factor xenofóbico aunque no fuera mencionado, también estaría presente en una etnografia realizada en un cortadero de ladrillos en la provincia de Córdoba. La autora, señalando un chiste que pronunciara el encargado de cortadero sobre los trabajadores bolivianos, dijo: "me sorprendió su actitud porque su piel es bien morena y también fue trabajador inmigrante, al igual que los bolivianos, sin embargo se identifica con los patrones gringos y reproduce la discriminación y la desigualdad laboral" (PIZARRO, 2009, p. 10). Es decir, la legitimación de la explotación de los trabajadores llegados de Bolivia no se produce en virtud de una invisibilización o enajenación cromática, sino que es posibilitada por la identificación con los propietarios, debido a los vínculos paternalistas que en la ponencia se ponen de manifiesto, pero también gracias a una ideología xenofóbica "anti-latinoamericana".
} 
ilusoriamente la integración social, ya que el sentimiento nacionalista tiene el efecto de aunarlos, hermanarlos aunque formalmente con el resto de la sociedad, incluyendo a quienes los explotan.

\section{Conclusiones}

Las clases sociales además de condicionales materiales de existencia, presentan simultáneamente valoraciones sociales. En una sociedad con profundas desigualdades y contradicciones, a cada clase y sector de clase le corresponden al mismo tiempo ponderaciones. $\mathrm{Y}$ al sector más depreciado de la clase asalariada le concierne una valía también depreciada. Lo cual se explicita, por ejemplo, en las referencias alternativas, equivalentes $\mathrm{y}$ degradantes: "mugriento", "no-ser gente", "villero", "negro", pero también en diversas prácticas discriminatorias. Prácticas que también son desarrolladas por el Estado.

Se trata de una segunda victimización. Esto es, además de sufrir un conjunto de condiciones materiales de existencia, soportan subjetividades estigmatizantes y acciones discriminatorias que indican inequívocamente inferiorización.

Sin embargo, los degradados y discriminados en ocasiones ejecutan (o reproducen) estigmas xenofóbicos, sobre trabajadores proveniente de países limítrofes. Tal como lo hace el resto de la sociedad con ellos, intentan separarse de los obreros recién advenidos también inferiorizándolos.

La percepción que este sector de la clase obrera tiene acerca de la estigmatización que sufre, es más bien de carácter empírico. Es decir, más allá de la valoración degradante, lo que reconocen estas personas son las diversas prácticas discriminatorias propiamente dichas, entre las cuales llegan a involucrar la inacción, desatención o acción insuficiente por parte del Estado -aunque lo expresen con el término de gobierno.

Asimismo, el motivo de la discriminación desde el punto de vista de los entrevistados sería el simple hecho de la condición por la que atraviesan, la pobreza.

Pero más allá de este parecer, tanto la degradación como la discriminación cuentan con un efecto en alguna medida oculto. Básicamente 
se trata de deslegitimar cualquier reclamo y/o acción de mejora de las diversas situaciones que atraviesan, y paralelamente legitimar tales circunstancias. Al ser inferiorizados, sus demandas por más necesarias y justas que fuesen, pasan a ser no-necesarias, no-justas, no-prioritarias. Lo cual en definitiva no hace más que de algún modo responsabilizarlos por las condiciones en las que desenvuelven sus vidas. En otras palabras, la estigmatización y la discriminación poseen también un objetivo, una finalidad, constituyen un instrumento.

Puede afirmarse, entonces, que tanto la degradación como la discriminación a los sectores más deprimidos del proletariado es inherente a una sociedad de clases con marcadas diferencias sociales, ya que por un lado, expresa la valía imperante sobre estos estratos, al tiempo que ostenta la funcionalidad de legitimar las condiciones de vida que los mismos sobrellevan, de cara a la incapacidad sistémica para su modificación estructural.

\section{Reflexiones sobre la labor etnográfica}

El trabajo de campo en estas villas fue y es posible en virtud de tres condiciones. En primer lugar, gracias al "contacto" realizado con algunas "referentes" -devenidas en "informantes claves"- de estas villas por un trabajador de E.P.E.C. El vínculo entre este asalariado (a quien se denominará como "José") y algunas/os pobladores de El Chaparral y Nueva Esperanza es de suma confianza y respeto. "José" para ellos es una persona que los ayuda a solucionar muchos problemas, los cuales en no pocas ocasiones nada tienen que ver con el suministro eléctrico. Llegar a estos lugares presentado por "José" habilitó que la confianza suministrada a éste, en cierto grado fuera trasladada al investigador. En segundo término, el investigador luego de explicitar los intereses del trabajo etnográfico $\mathrm{y}$, al mismo tiempo, de cierta apertura para escuchar lo que los investigados querian contar inicialmente, logró que la confianza inicial creciera. Ello permitió la apertura paulatina de los investigados incluso que el número de éstos se incrementara. Por último, existía y aún existe cierto número de personas básicamente interesadas y dispuestas a contar sobre sus vidas. En 
sintesis, el trabajo pudo realizarse por la confianza primeramente otorgada a y luego revalidada por el investigador, pero también por la decisión favorable de los investigados.

Ahora bien y en relación con esto último, las voces, los testimonios fueron dados por dos razones no del todo separables. Por un lado, querian mostrar las condiciones en que viven y por el otro, ser escuchados por alguien externo a la villa y que de alguna manera pudiera dar cuenta de sus circunstancias. Lo cual se vincula con el deseo de que "el gobierno" los reubique en un barrio. No obstante y obviamente también hubo muchos pobladores que no quisieron participar, a pesar de sus aspiraciones de abandonar la villa. En esta negativa cierto grado de vergüenza por hablar de las situaciones que atraviesan, al tiempo que la falta de expectativas en la modificación de sus condiciones de vida, primó.

Con relación a la esfera metodológica, el trabajo involucró las técnicas clásicas de entrevistas no dirigidas -aunque con ciertos lineamientos temáticos como horizontes- y observación participante, acompañadas por una permanente reflexividad y en articulación con teoría (GUBER, 2011, p. 44). Esto es, se reflexiona sobre la "voz del nativo" pero también sobre lo que el "nativo" hace. O mejor dicho, la reflexión es sobre la relación entre lo que se dice y lo que se hace, considerando también la dimensión teórica desde la cual el investigador elige pensar lo que el investigado dice y hace.

\section{Bibliografía}

ADAMOVSKY, Ezequiel. El color de la nación argentina. Conflictos y negociaciones por la definición de un ethos nacional, de la crisis al Bicentenario. Jahrbuch für Geschichte Lateinamerickas, Alemania, v. 49, n. 1, 2012.

BLÁZQUEZ, Gustavo. Negros de Alma. Raza y procesos de subjetivación juveniles en torno a los bailes de cuarteto (Córdoba, Argentina). Estudios de Antropologia Social, Buenos Aires, v. 1, Año 1, 2008.

FRIGERIO, Alejandro. Luis D`ELÍA y los negros: identificaciones raciales y de clase en sectores populares. Claroscuro. Revista del Centro de Estudios sobre diversidad Cultural, Rosario, v. VIII, n. 8, 2009.

FRONDIZI, Silvio. E1 Estado moderno. Ensayo de critica constructiva. Buenos Aires: Roque Desalma editor, 1954. 
GOFFMAN, Erving. Estigma. La identidad deteriorada. Buenos Aires: Amarrortu, 2006.

GUBER, Rosana. La etnografia. Método, campo y reflexividad. Buenos Aires: Siglo Veintiuno editores, 2011.

KAUFFMAN, Alejandro. Notas sobre la violencia discriminatoria "espontánea". En CAGGIANO, Sergio. Racismo, violencia y política. Pensar el Indoamericano dos años después. Buenos Aires: Universidad de General Sarmiento, 2012.

MAGLIANO, María José \& MALLIMACI BARRAL, Ana Inés. Migraciones, género $\mathrm{y}$ cuidados en Argentina: jerarquizaciones, desigualdades $\mathrm{y}$ movilidades. En PERISSINOTTI, María Victoria \& ZENKLUSEN, Denise. Los nudos ciegos de la desigualdad. Diálogos entre migraciones y cuidado. Córdoba: CIECS-CONICET, 2016.

MARX, Karl. El capital Libro I. Crítica de la economía política. México: Fondo de Cultura Económica, 2008.

PIZARRO, Cynthia. Olor a negro. Discurso, discriminación y segmentación étnica en el lugar de trabajo. Ponencia presentada en IV Coloquio de la Asociación Latinoamericana de Análisis del Discurso. Universidad Nacional de Córdoba, 2009.

SARTRE, Jean Paul. Colonialismo y neocolonialismo. Buenos Aires: Editorial Losada, 1968.

WACQUANT, Loïc. Parias urbanos. Buenos Aires: Manantial, 2010. 